\title{
SCHOPENHAUER' E A 'LIBERDADE DE SER O QUE SE É”, POR UMA ALEGORIA DE KAFKA EM UM ARTISTA DA FOME
}

\author{
Schopenhauer and the 'freedom of the will's \\ impossibility by Kafka allegory's in an \\ artist of the hunger
}

\section{Leandro Chevitarese}

Doutor e Mestre em Filosofia (PUC-Rio), Graduado em Filosofia (UERJ).

Professor do Curso de Especialização em Filosofia Contemporânea (Pós-graduação

Lato Sensu) da PUC - Rio de Janeiro - RJ. e-mail: leandrochevitarese @yahoo.com.br

\begin{abstract}
SCHOPENHAUER, A. Die welt als wille und vorstellung. Sämmtliche Werke. Textkritisch bearbeitet und herausgegeben von Wolfgang Frhr. von Löhneysen. Frankfurt am Main: Suhrkamp, 1986. Abreviaturas e traduções utilizadas: MVR - Le Monde comme Volonté et comme Représentation. Trad. A. Burdeau (nouv. éd. rév. et corr. par R. Roos). Paris: Press Universitaires de France, 13. éd., 1992; O Mundo como Vontade e como Representação. Trad. Jair Barboza. SP: UNESP, 2005. SPL - Supplément. In: Le Monde comme Volonté et comme Représentation. Trad. A. Burdeau (nouv. éd. rév. et corr. par R. Roos). Paris: Press Universitaires de France, $13^{\mathrm{a}}$ éd., 1992; PP - Parerga and Paralipomena. Trad. E. F. J. Payne. Vol. I e II. New York: Oxford University Press, 2000; Parerga e Paralipomena. Caps. V, VIII, XII, XIV. Trad. M. L. M. O. Cacciola. SP: Nova Cultural., 1991. LV - Essai sur le Libre Arbitre. Trad. Salomon Reinach. Paris: Librarie Félix-Alcan, 1913. ASV Aforismos para a Sabedoria de Vida. Trad. Jair Barboza. SP: Martins Fontes, 2002. SFM Sobre o fundamento da moral. Trad. Maria Lúcia M. O. Cacciola. SP: Martins Fontes, 1995. Obs.: As referências às páginas seguirão sempre a ordem de apresentação das traduções. Por exemplo, (MVR, p.trad. em francês, p.trad. em português) ou (LV, p.trad. em francês).
\end{abstract}




\title{
Resumo
}

Uma alegoria de Kafka é apresentada, a qual pode ser encontrada em uma de suas histórias chamada "Um Artista da Fome". A intenção desta apresentação é mostrar o conceito filosófico de Schopenhauer na "liberdade de ser o que se é". Uma pesquisa tem sido feita nos temas de Schopenhauer sobre responsabilidade, arrependimento. Finalmente, é considerada a possibilidade de entender "a impossibilidade de falhar ser no que se supõe que um é", como uma oportunidade de "fazer arte do que se é".

Palavras-chave: Liberdade; Vontade; Responsabilidade.

\begin{abstract}
An allegory of Kafka is presented, one that can be found in his tale entitled "An Artist of Hunger". The presentation is intenteded to highlight the Shopenhauerian philosophical concept of "freedom of the will's impossibility". An investigation is undertaken of Shopenhauer's themes of responsability, regret and repent. Finally it's considered the possibility of understanding of "the impossibility of failing to be whatever one is", as an oportunity of "making art out of what one is".
\end{abstract}

Keywords: Freedom; Will; Responsibility.

A primeira conversa filosófica entre Kafka e Max Brod, a conversa que "selou" a amizade de ambos, parece ter acontecido, segundo a biografia de Kafka por Brod, após uma conferência sobre Schopenhauer, feita pelo jovem estudante universitário Brod, em 1902, num clube acadêmico alemão de Praga e, embora Kafka talvez nunca tenha estudado sistematicamente a obra de Schopenhauer, este filósofo - e não pouco devido a Max Brod - estava bem presente na atmosfera intelectual na qual ele cresceu. As Obras Completas de Schopenhauer figuravam entre os livros possuídos por Kafka. (HELLER, 1976, p. 34). 
A bibliografia de comentadores de Kafka, como se sabe, é vastíssima. Alguns, como Heller, procuraram explorar a relação entre Kafka e Schopenhauer. De fato, seja pelo viés biográfico, seja pela afinidade temática ou a influência teórica, é possível articular inúmeras proximidades entre o escritor e o filósofo. E isso não se aplica somente a Kafka. A influência da filosofia de Schopenhauer pode ser interessantemente observada em diversos expoentes da literatura mundial, tais como Proust, Mann, Beckett, Borges, além, é claro, de Machado de Assis.

Entretanto, não é objetivo do presente artigo construir relações ou comparações entre os dois, ou mesmo argumentar em favor de um "schopenhaurianismo" presente em Kafka - embora isso pareça bastante plausível. ${ }^{2}$ Pretende-se, com efeito, apresentar uma alegoria de Kafka, presente em seu conto intitulado Um Artista da Fome (Ein Hungerkünstler), como uma forma de dar visibilidade ao conceito filosófico schopenhaueriano de "impossibilidade de liberdade da vontade" por meio da imagem construída pelo escritor. É fundamental frisar, no entanto, que não se trata aqui de uma interpretação da obra de Kafka, mas, sim, de uma reflexão filosófica a partir de uma alegoria kafkiana. Não se pretende também, de modo algum, uma avaliação ou julgamento da obra de Kafka, pois, obviamente, não se pode considerar o valor de uma obra literária em função da visão de mundo que ela parece expressar. ${ }^{3}$ Trata-se, pois, de um recurso alegórico, enquanto fomento para reflexão sobre uma importante questão da filosofia de Schopenhauer.

Para que se possa considerar essa alegoria de Kafka em sua contribuição à questão da liberdade da vontade, faz-se necessário abordar, ainda que brevemente, a compreensão de Schopenhauer sobre a obra de arte alegórica.

Schopenhauer nos apresenta a arte como a contemplação do mundo como representação, independente do princípio de razão, ou véu de Maya. Sua finalidade essencial é comunicar a idéia concebida pelo artista. A idéia é "a objetidade (objektität) imediata e por isso adequada da coisa em si” (MVR § 32, p. 226-241), sendo objeto de um conhecimento intuitivo. Por meio do artista, tal

2 As notas de rodapé que traçam alguns comentários sobre a visão kafkiana da esperança, da liberdade e do "mal de viver" sugerem tal plausibilidade. Entretanto, essas considerações têm aqui, exclusivamente, um caráter ilustrativo.

3 Como muito bem observa Ramos: "é muito grande o risco de acabar por reduzir uma peça de Samuel Beckett, um romance de Thomas Mann ou um conto de Machado de Assis a uma ou outra tese da filosofia de Schopenhauer, e cair no erro que consiste em subordinar o valor de uma obra literária apenas à visão de mundo que ela expressa” (RAMOS, 2004, p. 75). 
idéia torna-se intuitivamente compreensível mesmo para uma inteligência fraca, embora ela só se revele a cada um de acordo com suas próprias possibilidades. Não cabe à arte, portanto, expressar conceitos - que nada mais são do que uma representação abstrata e discursiva. Nessa rejeição à pretensão de expressar conceitos por meio da arte repousa o fundamento da crítica de Schopenhauer à alegoria nas artes plásticas, desenvolvida no parágrafo 50 de MVR.

Na medida em que a alegoria tem "sempre por missão figurar um conceito", quando aplicada às artes plásticas, "o espírito do espectador é desviado da representação intuitiva exposta e conduzido a uma outra representação, não intuitiva, mas abstrata e que reside por completo fora da obra de arte" (MVR § 50, p. 304-314). Nas artes plásticas, as alegorias assumem o caráter de meros hieróglifos, fim similar ao da escrita, sendo que ela é muito mais adequada para atingir tal fim. Logo, se o propósito em questão é comunicar conceitos abstratos, então é o caso de recorrer à escrita e não às artes plásticas.

Deste modo, se um quadro alegórico tem algum valor artístico, certamente, esse valor não lhe é dado pela alegoria que apresenta. Tal situação seria comparável a de um objeto de arte que é, simultaneamente, um objeto útil: certamente, seu valor artístico em nada se relaciona com seus possíveis usos.

Para que a finalidade da arte seja atingida, é imprescindível que a obra de arte expresse idéias e não conceitos - como é o caso da alegoria. Portanto, sua concepção de arte leva Schopenhauer a afirmar que o emprego de alegorias nas artes plásticas seria uma "tendência equivocada" que se torna "absolutamente insuportável” (MVR § 50, p. 316).

Todavia, o filósofo afirma que, se nas artes plásticas, a alegoria é inaceitável, por outro lado, na poesia "é admissível e mesmo bastante útil" (MVR $\S 50$, p. 308 -317). Isso se deve ao fato de que a poesia nos oferece diretamente conceitos, por meio das palavras que emprega, sendo a tarefa do artista, precisamente, conduzir-nos do conceito à intuição. Por meio das palavras, o poeta abre a possibilidade de comunicar a idéia por ele contemplada, o que só pode acontecer por meio da passagem do conceito abstrato e discursivo para o conhecimento intuitivo. Esse fenômeno pode ser observado em "cada expressão figurada, em cada metáfora, comparação, parábola e alegoria" (MVR § 50, p. 309-318). Todas elas expressam o conceito por meio de uma imagem. Como afirmou Schopenhauer em suas preleções sobre a Metafísica do Belo, na universidade de Berlim: "caso não se expresse o conceito ou pensamento mesmo, mas simplesmente se institua a imagem, permitindo ao ouvinte passar desta para o pensamento, tem-se a alegoria, à qual pertence também a fábula e a parábola, que são alegorias precisas" (SCHOPENHAUER, 2003, p. 189). 
Uma alegoria poética pode ter um sentido filosófico profundo. ${ }^{4} E$ com entusiasmo que Schopenhauer se refere a mais famosa alegoria da história da filosofia: a alegoria da caverna de Platão. O filósofo sempre foi um grande apreciador de literatura e, ao longo de sua obra, não poupa elogios a diversos autores, tanto antigos como modernos; mas, ao destacar obras alegóricas importantes, ${ }^{5}$ menciona particularmente três:

Três obras literárias alegóricas pormenorizadas me são conhecidas: uma, aberta e confessadamente é o Criticon de Baltasar Gracián; que consiste num grande e rico entrançamento de alegorias altamente engenhosas, servindo como discreta vestimenta a verdades morais, às quais o autor transmite enorme possibilidade de apreensão intuitiva e assim nos coloca em estado de espanto com a riqueza de suas invenções. Duas outras obras, no entanto veladas, são o Dom Quixote e Gulliver em Liliput. (MVR § 50, p. 309-319).

Cabe enfatizar que, na alegoria poética, "conceito é sempre dado, que ela procura tornar intuível por uma imagem" (MVR § 50, p. 310-319, meus grifos). A finalidade da arte seria atingida quando, por fim, passa-se do conceito à intuição.

4 No contexto de sua grave crítica à religião, ao tratar da Necessidade Metafísica do Homem, Schopenhauer enfatiza o caráter alegórico das religiões. Cabe um breve esclarecimento sobre isso. Segundo o filósofo, os sintomas dessa natureza alegórica são os mistérios presentes em todas as religiões, constituindo um modo de "se fazerem sentir pelo senso comum" (SPL, p. 859). Tal natureza alegórica acaba por dispensar as demonstrações e reflexões críticas próprias à filosofia. As religiões vêm suprir a necessidade metafísica humana, preenchendo, na grande massa, o espaço que deveria ser reservado à Metafísica enquanto atividade filosófica. Nesse contexto, é importante frisar que a crítica de Schopenhauer não se dirige à alegoria per se, mas, de fato, ao papel que ela ocupa nas religiões, que, "não podem jamais confessar sua natureza alegórica; são obrigadas a se apresentar como verdadeiras sensu próprio " (SPL, p. 860).

5 Como se sabe, Schopenhauer foi também um grande admirador da literatura oriental, fazendo diversas referências a obras como o Mahabharata e o Bhagavad Gita, como também ao Prabodha-Chandrodaya, que descreve como um "drama filosófico-alegórico de tanta importância para a filosofia vedanta”. (PP § 110, p. 203 e 189). Segundo Radhakrishnan, um dos mais importantes historiadores da filosofia indiana, esse drama filosófico afirma que os seis sistemas da filosofia hindu não são mutuamente excludentes, mas estabelecem diferentes pontos de vista sobre o mesmo tema. Esse drama é discutido em sua obra, particularmente, no contexto de apresentação do materialismo indiano. (RADAKRISHNAN, 1923 , v. 1, p. 48 e cap.V.) 
Como se sabe, o próprio Schopenhauer não somente citou e empregou diversas alegorias poéticas ao longo de sua própria obra, como também se dedicou a escrevê-las, organizando-as no último capítulo de PP, intitulado "Símiles, parábolas e fábulas" (Gleichnisse, Parabeln und Fabeln). Deste modo, seguindo a concepção schopenhaueriana de alegoria poética, a proposta deste recurso alegórico a partir da obra de Kafka é "tornar visível um conceito por uma imagem", no caso, o conceito de "impossibilidade de liberdade da vontade". A partir dessa alegoria, pretende-se explorar a alternativa de compreender tal conceito como a "liberdade de ser o que se é", que nada mais seria do que a "liberdade que nos resta". Vejamos.

Em Um Artista da Fome, ${ }^{7}$ Kafka nos apresenta um jejuador que outrora foi uma grande atração pública. Antigamente, relata Kafka, "toda a cidade se ocupava com os artistas da fome". O interesse coletivo aumentava com o passar dos dias, todos queriam assistir àquele homem que resistia à fome e recusava todo alimento. Vigilantes escolhidos pelo público acompanhavam dia e noite o jejuador, para garantir que ele não se alimentasse ocultamente. E isso atormentava por demais o jejuador: "às vezes, superando a fraqueza, ele cantava, enquanto tinha forças, no período de vigia, para mostrar as pessoas como era injusto suspeitarem dele". O artista, de fato, "jejuava como nenhum deles seria capaz", mas, ainda sim, estranhamente, era muito fácil para ele jejuar. "Ele não o ocultava, mas não acreditavam nele; no melhor dos casos consideravam-no modesto". O período máximo em que permanecia jejuando era de quarenta dias - prazo fixado pelo empresário, durante o qual se podia garantir o assédio e interesse pelo artista. Mas o dejejum era para ele sempre desagradável, não somente pelas náuseas que sentia apenas em pensar no que comeria, como também porque o impediam de continuar jejuando. "Ele poderia agüentar ainda muito tempo, um tempo ilimitado; por que suspender agora quando estava no melhor, isto é, ainda não estava no melhor do jejum?". O desjejum era sempre um grande espetáculo, orquestrado nos mínimos detalhes pelo empresário para o deleite da platéia - apenas o artista da fome permanecia insatisfeito, pela interrupção de sua arte.

6 Algumas dessas alegorias se tornaram bastante conhecidas, dentre as quais a mais famosa é, provavelmente, a "fábula dos porcos-espinhos" (PP § 396, vol. II, p. 651/652). De acordo com sua concepção de alegoria poética, Schopenhauer pretende com elas tornar compreensível um conceito por meio de uma imagem. É nesse sentido, por exemplo, que se refere, em ASV, à "fábula dos porcos-spinhos": ao tratar do tema da sociabilidade e da solidão, o filósofo remete o leitor para essa fábula, imaginada por ele sobre este assunto (ASV, p. 168).

7 KAFKA, F. Um artista da fome e a construção. Trad. Modesto Carone. SP: Companhia das Letras, 1998. As citações que se seguem podem ser encontradas nas páginas 23-30. 
Essa dinâmica se repetiu por anos a fio, até que "o artista da fome se viu um dia abandonado pela multidão ávida de diversão que preferia afluir a outros espetáculos". Com suas perspectivas de trabalho reduzidas, um tanto pelo fama de outrora que não o permitia entregar-se a pequenas feiras sem importância, separou-se de seu antigo empresário para empregar-se em um grande circo. Não ocupou ali nenhum lugar de destaque, ficando sua jaula próxima aos estábulos. Nos intervalos das grandes atrações, quando o público se dedicava a visitar os animais, o jejuador era observado pelos passantes. No início, estas eram as horas mais ansiadas pelo artista. Entretanto, logo deixou de lado esse auto-engano, convencendo-se de que "o objetivo daquelas pessoas era sempre, sem exceção, visitar os estábulos". Sua arte não chamava mais a atenção como antes, ainda que jejuasse "tão bem quanto quisesse - e ele o fazia - mas nada mais podia salvá-lo". O desinteresse geral concorreu para que ninguém mais contasse os dias do jejum, "nem mesmo o jejuador conhecia a extensão de seu desempenho". A jaula permaneceu abandonada, os cartazes ficaram ilegíveis, esquecidos, até que, após muitos dias[...].

[...] um inspetor notou a jaula e perguntou aos serventes por que deixavam sem uso aquela peça perfeitamente aproveitável com palha apodrecida dentro; ninguém sabia, até que um deles, com ajuda da tabuleta, se lembrou do artista da fome. Levantaram a palha com ancinhos e encontraram nela o jejuador. (KAFKA, 1998, p. 23-30). quando vai parar?

- Você continua jejuando? - perguntou o inspetor. - Afinal

- Peço desculpas a todos - sussurrou o artista da fome; só o inspetor, que estava com o ouvido colado às grades, o entendia.

- Sem dúvida - disse o inspetor, colocando o dedo na testa, para indicar aos funcionários, com isso, o estado mental do jejuador. - Nós o perdoamos. artista da fome.

- Eu sempre quis que vocês admirassem meu jejum - disse o haveríamos de admirar?

- Nós o admiramos - retrucou o inspetor. - Por que não

- Mas não deviam admirar - disse o jejuador.

- Bem, então não admiramos - disse o inspetor. - Por que é que não devemos admirar?

- Por que eu preciso jejuar, não posso evitá-lo - disse o artista da fome. 
- Bem se vê - disse o inspetor. - E por que não pode evitá-lo?

- Por que eu - disse o jejuador, levantando um pouco a cabecinha e falando dentro da orelha do inspetor com os lábios em ponta, como se fosse um beijo, para que nada se perdesse. - Porque eu não pude encontrar o alimento que me agrada. Se eu o tivesse encontrado, pode acreditar, não teria feito nenhum alarde e me empanturrado como você e todo mundo.

Estas foram suas últimas palavras, mas nos seus olhos embaciados persistia a conviç̧ão firme, embora não mais orgulhosa, de que continuava jejuando.

$\mathrm{O}$ artista da fome jejuava apenas porque não podia evitar: jamais encontrara um alimento que lhe desse apetite. Em momento algum, o artista "pôde escolher" seu ofício: era um jejuador porque lhe era inevitável. Seu ofício e todas as suas ações foram uma decorrência direta de seu caráter, que jamais foi objeto de escolha e que nunca mudou. As últimas palavras do artista indicam, inclusive, que gostaria muito de ser como os outros e se empanturrar à vontade, mas essa liberdade que anseia é impossível. " "Ninguém se torna isto ou aquilo, por mais que queira sê-lo" (PP § 118, p. 209-231). O artista só poderia abandonar seu ofício se tivesse outro caráter, se fosse outra pessoa - condição pela qual poderia querer diferente. Em suma: artistas da fome sempre jejuam porque não podem deixar de ser o que são. Isso corresponde a dizer: os homens sempre fazem o que fazem porque não podem evitar o que são.

É interessante que Magee, para ilustrar a impossibilidade de "escolher o que se quer", também emprega um exemplo gastronômico:

Se eu peço uma refeição em um restaurante, posso ser livre para escolher o que eu gosto entre as alternativas do cardápio. Mas não sou livre para escolher aquilo de que irei gostar. Não posso dizer para mim mesmo: "até este momento de minha vida eu sempre detestei espinafre, mas somente hoje vou gostar”. (MAGGE, 1983, p. 190).

8 Sobre a liberdade em Kafka, seguindo o argumento de Anders, pode-se dizer que ela corresponde a "ser admitido" - como aparece em sua obra O Castelo - ou entrar na lei" como na famosa alegoria anunciada pelo sacerdote no Cap. IX de O Processo. Todavia, como observa Anders, "quem quer chegar, não quer estar livre. Por isso, a liberdade é o sonho de angústia de Kafka “(ANDERS, 1969, p. 37). Em outras palavras, seria possível dizer: os personagens kafkianos querem atingir o impossível. 
No caso do artista da fome, certamente ele não poderia escolher nenhuma das opções oferecidas no cardápio, por mais que invejasse aqueles que, efetivamente, podem fazer seus pedidos ao garçom. $\mathrm{O}$ artista da fome não pode se livrar de suas impossibilidades, de suas limitações. Ele simplesmente não pode deixar de ser o que é. O Artista da Fome, de Kafka, de fato, pode ser tomado como uma interessante alegoria, ou seja, uma figuração em imagem do conceito schopenhaueriano de recusa à liberdade da vontade, que corresponde à "impossibilidade de deixar de ser o que se é".

É possível, ainda, explorar outro aspecto da imagem de Kafka. Como compreender as "desculpas" do artista na hora da morte? Do que seria o artista "culpado"? Qual seria sua responsabilidade? Em outras palavras, como compreender a responsabilidade de alguém que não pode evitar o que é?

Certamente, ele não poderia evitar a culpa e a vergonha inalienável de existir ${ }^{9}$ - e vale lembrar, ilustrativamente, as últimas palavras do protagonista do romance $O$ Processo de Kafka: "era como se a vergonha devesse sobreviver a ele" (KAFKA, 1992, p. 246). Para Schopenhauer, "no fundo, cada individualidade é apenas um erro especial, um passo em falso, algo que seria melhor não ser" (SCHOPENHAUER, 2000, p. 110), por isso, recomenda que se diga para aquele que morre: "Tu cessas de ser algo, que terias feito melhor, nunca ter sido" (SCHOPENHAUER, 2000, p. 127). Todavia, o artista pede desculpas, não propriamente por sua existência, mas porque queria ser admirado como jejuador. Como compreender sua responsabilidade diante de algo que lhe era inevitável?

9 Em sua interpretação da obra de Kafka, afirma que "a Lei sem legislador, o pecado original sem um Deus a ser obedecido" constitui a essência da teologia negativa kafkiana: "trata-se de uma situação em que o pecado e a culpa parecem residir, com mais freqüência, no ato de ser e não em qualquer ato, em ser um indivíduo isolado; ou, para usar as palavras de Schopenhauer, no próprio principium individuationis, [...]". (HELLER, 1976, p. 34). Martial Gueroult, em sua introdução à tradução brasileira de Metafísica do Amor e Metafísica da Morte, respectivamente, Suplementos XLIV e XLI ao MVR, propõe a interpretação de que "o mal maior é existir; ainda melhor, existir é o pecado original" (HELLER, 1976, p. 33) - o que se aproxima bastante da interpretação de Heller sobre Kafka.

10 Sobre a morte, Schopenhauer afirma que "é a grande correção que a vontade de viver, e o egoísmo essencial a ela, recebem do curso da natureza e que pode ser concebida como uma punição para nossa existência. É o desatar doloroso do nó, que a procriação amarrou com volúpia e é a destruição violenta, proveniente de fora, do erro fundamental de nosso ser: a grande desilusão. No fundo somos algo que não deveria ser e, por isso, deixamos de ser" (SCHOPENHAUER, 2000, p. 137). 
Em geral, considera-se a responsabilidade como algo que depende da liberdade de poder "agir diferente": na medida em que se é livre para agir, se é responsável pelo que se faz. Todavia, para o filósofo da vontade, não se pode evitar o que se é, e todos os nossos atos são uma consequiência direta de nosso caráter: "operari sequitur esse". Deste modo, com certeza, a responsabilidade em Schopenhauer não pode ser considerada apenas à luz de uma responsabilidade pela ação que, supostamente, poderíamos cometer ou não. No último capítulo de seu ensaio premiado Sobre a Liberdade da Vontade, o filósofo, após demonstrar a impossibilidade de liberdade da vontade, elabora uma "consideração mais elevada" sobre o tema. Schopenhauer procura enfatizar que a recusa à liberdade empírica nos leva a considerar que a verdadeira liberdade moral "pertence a uma ordem de idéias superior" (LV, p. 185). A consciência atesta a verdade perfeitamente clara de nossa responsabilidade moral e da imputabilidade de nossos atos: "tal sentimento repousa na convicção inabalável que somos nós mesmos os autores de nossos atos" (LV, p. 185). Este sentimento de responsabilidade "só se refere ao próprio ato mediatamente e em aparência: no fundo, é sobre o seu caráter que ela recai, é de seu caráter que ele se sente responsável" (LV, p. 186).

Deste modo, a responsabilidade se inscreve de modo muito mais radical e profundo, pois repousa em nosso próprio ser: "como o homem é, assim é obrigado a agir, portanto, não aos seus atos individuais, mas a seu ser e essência se prendem culpa e mérito" (PP $\S 118$, p. 236 e 213). O sentimento de responsabilidade é um sintoma da liberdade moral que é própria ao nosso caráter: "onde há culpa deve existir igualmente responsabilidade" (LV, p. 187). Como afirma Vecchiotti, deste modo sempre "teremos um sentimento perfeitamente claro da imputabilidade de nossos próprios atos. Por isso cada qual aceita a própria responsabilidade, como aceita a própria culpa" (VECCHIOTTI, 1986, p. 53). Entretanto, Vecchiotti faz disso uma interpretação um tanto problemática: "mas a teoria apresentada por Schopenhauer parece ser antes uma teoria da responsabilidade da vontade através do homem: na medida em que, como caracteres inteligíveis, pertencemos à essência da vontade, somos responsáveis" (VECCHIOTTI, 1986, p. 53).

Ainda que Vecchiotti esteja certo em dizer que a "liberdade moral autêntica" não se encontra no plano empírico - pertencendo a "uma ordem superior" -, são muito problemáticas as conclusões que retira disso. Não parece adequada a interpretação de que "pertencemos à essência da vontade", muito mais apropriado seria afirmar que "nossa essência é a vontade, por isso, somos sempre responsáveis", pois, afinal, como distinguir nosso verdadeiro ser de 
nós mesmos? A interpretação de Vecchiotti pode sugerir o equívoco de, per abusurdum, culpar ou responsabilizar a vontade, que "nos torna culpados" (!) por que se manifesta em nós. Bem melhor é a formulação de Cacciola, que afirma, em relação ao homem, que "a responsabilidade moral repousa, pois, sobre seu caráter, sobre o seu 'eu quero' que acompanha todas as nossas ações" (CACCIOLA, 1994, p. 168).

Como vimos, o caráter empírico é uma tradução de nosso invariável caráter inteligível - este, sim, obra de nossa verdadeira liberdade, fora do tempo, do espaço e da causalidade -, constituindo-se como uma manifestação dele. "A liberdade não pertence ao caráter empírico, mas tão-só ao inteligível” (SFM, p. 91). De fato, o lugar da liberdade anuncia onde repousa toda a responsabilidade, que se desloca, portanto, das ações (que supostamente poderíamos não realizar), para se inscrever de modo muito mais radical em nosso caráter inteligível, nosso próprio ser. Somos inexoravelmente responsáveis por tudo o que fazemos e sofremos: "nós conhecemos no que fazemos aquilo que somos; por aquilo que sofremos, conhecemos aquilo que merecemos" (PP § 116, p. 207-227). Nossa história de vida é de nossa inteira responsabilidade e, do mesmo modo, todos os homens são responsáveis pela história da humanidade. O artista da fome é, certamente, responsável por seu "esse", pois "ele poderia ter sido outro: e naquilo que ele é estão culpa e mérito" (SFM, p. 91). Por isso, o artista - como qualquer indivíduo - é responsável por seu caráter, pelos atos que dele decorrem e por todo seu sofrimento, por isso, a "culpa" que ele quer "des-culpar".

Todavia, é possível explorar ainda mais essa imagem. Como compreender o sentido das "desculpas" do artista? Não se pode esquecer que "as censuras da consciência dizem respeito, em primeiro lugar e ostensivamente, àquilo que fizemos, mas, propriamente no fundo, àquilo que somos" (SFM, p. 190). Entretanto, segundo Schopenhauer, é possível ainda distinguir dois tipos de censura: o remorso - ou "peso da consciência" - (remords/Gewissensangst) e o arrependimento (regret/Reue). Deste modo, cabe perguntar: excetuando a própria "vergonha de existir", e considerando a responsabilidade integral por tudo o que se faz e se padece, que sentido pode ter o ato de "desculpar-se"?

No parágrafo 55 de MVR, que trata do caráter e da liberdade da vontade, Schopenhauer concebe o remorso como uma "dor sobre o conhecimento de nosso si mesmo, ou seja, como Vontade. Baseia-se na certeza de que sempre temos a mesma vontade" (MVR $§ 55$, p. 377-384). No parágrafo 62, que trata da justiça e do direito, Schopenhauer acrescenta que o remorso é o sentimento proveniente da injustiça cometida. Por fim, no parágrafo 65, ao analisar o significado essencial do mal, o filósofo observa que "como sentimento 
- ou seja, não como conhecimento claro, abstrato - constitui o conteúdo do peso de consciência" (MVR § 65, p. 462-468). Ora, se a malvadez está na base do remorso, que se configura como um sentimento de injustiça cometida e, por sua vez, pressupõe uma visão clara de nossa própria conduta, não parece razoável que o artista da fome se desculpe por remorso. Afinal, que injustiça ${ }^{11}$ poderia ele ter cometido? Que ato seu poderia ser expressão de um caráter malvado? ${ }^{12}$ De qualquer modo, é este um dos sentidos de compreensão de nossas "desculpas": o sentimento de remorso.

Poderia, então, o artista da fome estar arrependido? Segundo Schopenhauer, o remorso difere amplamente do arrependimento, que

Nunca se origina de a vontade ter mudado (algo impossível) mas de o conhecimento ter mudado [...]. Portanto nunca posso me arrepender do que quis, mas sim do que fiz, visto que, conduzido por falsas noções, agi de maneira diferente daquela adequada à minha vontade. (MVR § 55, p. 376-383).

O arrependimento surge por uma inadequação do querer em relação às ações cometidas. Ele exige uma correção da relação estabelecida entre um ato e seu verdadeiro objetivo. Como destaca Cacciola, na medida em que o conhecimento abstrato faz surgir "hesitação e incerteza", advém a "possibilidade do erro, que pode falsear as manifestações da vontade por meio de motivos aparentes que, nem por isso, deixam de ser eficazes" (CACCIOLA, 1994, p. 168).

De fato, a própria noção de "erro" só pode surgir por meio do intelecto, que produz representações abstratas. Aplicado à nossa conduta quando, por exemplo, dizemos que "erramos" - significa que reconhecemos a inadequação entre o que se fez e o que se queria (pelo menos conscientemente) fazer. Nem sempre o homem compreende bem seu caráter, "que se manifesta apenas no tempo, isto é, via ações, encontra uma resistência análoga no conhecimento, que quase nunca lhe fornece os dados inteiramente corretos, fazendo o ato não corresponder de maneira precisa e integral à Vontade, preparando dessa forma o arrependimento" (MVR § 55, p. 376-384). Este é um ponto particularmente importante: o conhecimento sobre o nosso imutável

11 Schopenhauer define a injustiça como a "invasão dos limites da afirmação alheia da vontade" (MVR § 62, p. 421-429), ou seja, a afirmação da vontade para além dos limites de seu próprio corpo.

12 Schopenhauer afirma que "uma pessoa sempre inclinada a praticar a injustiça, assim que a ocasião se apresente e nenhum poder a coíba, denominamos má.” (MVR § 65, p. 456-462). 
caráter pode evitar o arrependimento, visto que poderíamos melhor equacionar a relação entre nosso querer e nossos atos. Isso corresponde a um melhor encaminhamento de nossa vontade no curso da vida.

É provável que o pedido de desculpas do artista seja um arrependimento, uma constatação de que não soube agir perfeitamente de acordo com seu caráter. $O$ artista queria ser admirado como jejuador. Em face da afirmação de que era, de fato, admirado, retruca afirmando que não deveria ser admirado, pois só jejuava por que não conseguia evitar. A situação em que se encontra o jejuador é semelhante a de um cleptomaníaco que, flagrado em seu melhor furto, pede desculpas porque sempre "quis ser admirado em sua arte"; ou ainda, semelhante a de um homem compulsivamente caridoso, outrora rico, que, flagrado na absoluta mendicância, pede desculpas porque sempre "quis ser admirado em sua arte". Mas como poderia haver admiração por algo que não se pode deixar de fazer? A única admiração que o artista pode obter ao longo da vida se fez, na verdade, por uma incompreensão de sua arte. Ele não era o homem que "resistia bravamente" ao desejo de comer, mantendo-se firmemente em jejum por uma convicção, por um domínio de si mesmo - se assim fosse, haveria justificativa para a admiração. Mas ele, simplesmente, não podia evitá-lo.

Talvez, seu pedido de desculpas advenha do fato de que, em face da vontade de ser admirado, o único modo que conseguiu encontrar para encaminhar seus esforços foi pleitear admiração pelo que, na verdade, nunca fez. Somente por uma incompreensão de sua arte, o jejuador conseguiu ainda que por algum tempo - a admiração que ansiava. Poderia ele obter admiração pelo que lhe era inevitável? Se a resposta a essa pergunta for negativa, isso se aplica a todos nós. Nesse sentido, não há, absolutamente, homens admiráveis no mundo.

Todavia, tendo em vista a possibilidade do caráter adquirido, podese supor que o artista poderia modificar, não seu caráter, seu encaminhamento na vida. Como agiria então? Jamais saberemos tal resposta. Entretanto, podese dizer, de fato, que todas as suas ações continuariam a ser decorrências de seu caráter, embora pudesse se conduzir de modo mais prudente, evitando o sofrimento, o arrependimento e procurando uma vida "menos infeliz". Talvez aqui repouse a possibilidade de alguma admiração aos homens: a capacidade de "aprender a lidar com o que se é".

O conto de Kafka pode nos oferecer um interessante olhar sobre a tese schopenhaueriana que afirma a impossibilidade de liberdade da vontade. Se, por um lado, à primeira vista, a negação do "livre-arbítrio" pode nos sugerir limitação, restrição e até mesmo um fatalismo trágico que, em geral, suscita 
uma certa repugnância; por outro lado, é possível considerar a questão em termos de uma "impossibilidade de deixar de ser o que se é" articulada à possibilidade de aprender a lidar consigo mesmo. Isso só se pode fazer presente por meio do "autoconhecimento" implícito ao caráter adquirido. Tal condição exige, em primeiro lugar, a necessidade de abandonar a ilusão de que se possa "escolher o que se quer" - definitivamente, não podemos "querer o que queremos". Afastando toda a esperança, seja de um porvir redentor, seja de qualquer mudança no caráter - e vale lembrar que também "em Kafka, toda espera é vã"13 -, é possível destacar a importância concedida por Schopenhauer ao aprendizado que nos vem pela experiência, que constitui nosso caráter adquirido certamente, como vimos, um atributo de nosso intelecto espectador.

Além disso, outro aspecto interessante que pode ser explorado a partir da alegoria kafkiana é a oportunidade de compreender a "impossibilidade de deixar de ser o que se é" como uma chance de "fazer arte daquilo que se é". Conhecer nossas "impossibilidades" corresponde, simultaneamente, ao conhecimento de nossos potenciais, a partir do que abre-se a oportunidade de explorá-los amplamente. Investindo nas possibilidades inerentes àquilo que somos, ou seja, investindo naquilo que nos é inevitável, é possível "fazer arte daquilo que se é". Talvez, por isso, tenhamos a sensação de que, em geral, o que melhor fazemos na vida é, precisamente, aquilo que menos podemos evitar. Agimos porque nos é inevitável e nos conhecemos por meio de nossas ações. Somos, acima de tudo, o que nos é inevitável ser. Conhecendo o que não podemos evitar, conhecemos a nós mesmos e, compreendendo tudo o que podemos, percebemos nossas potencialidades e maiores habilidades. Em última análise, os melhores especialistas em qualquer atividade são, no fundo, grandes artistas de algo que lhes é inevitável.

13 HELLER, 1976, p. 75. Sobre a "esperança" em Kafka, Walter Benjamin escreveu: "Depreendemos de $O$ Processo que esse procedimento judicial não deixa via de regra nenhuma esperança aos acusados, mesmo quando subsiste a esperança da absolvição. É talvez essa desesperança que faz com que os acusados sejam os únicos personagens belos na galeria kafkiana. Essa hipótese estaria de acordo com um fragmento de diálogo, narrado por Max Brod. 'Recordo-me de uma conversa com Kafka, cujo ponto de partida foi a Europa contemporânea e a decadência da humanidade. Somos, disse ele, pensamentos niilistas, pensamentos suicidas, que surgem na cabeça de Deus. Essa frase evocou em mim a princípio a visão gnóstica do mundo: Deus como um demiurgo perverso, e o mundo como seu pecado original. Oh não, disse ele, nosso mundo é apenas um mau humor de Deus, um dos seus maus dias. Existiria então esperança, fora desse mundo de aparências que conhecemos? Ele riu: há esperança suficiente, esperança infinita - mas não para nós. (BENJAMIN, 1994, p. 141-142, meus grifos.) 
Este é um aspecto particularmente importante da argumentação que está sendo proposta na presente pesquisa. Em geral, o argumento de Schopenhauer que recusa à liberdade da vontade é compreendido apenas como radical limitação e uma inevitabilidade trágica - o que, de certo modo, é bastante veraz. Todavia, pode-se interpretá-lo, simultaneamente, como um convite para viver da melhor maneira possível, explorando intensamente nossos potenciais, investindo naquilo que melhor fazemos na vida, ou seja, um convite para "fazer arte do que nos é inevitável" - o que não pode prescindir do autoconhecimento, que pode nos mostrar se utilizamos mal os meios, tendo em vista o que queremos, ou seja, nosso caráter.

De fato, não é o caso de afirmar um fatalismo incondicional, como se nada houvesse a fazer e estivéssemos de mãos atadas e inteiramente entregues a um inexorável destino. Aliás, pode-se dizer que o texto dos Aforismos para a Sabedoria de Vida desmente francamente tal possibilidade. ${ }^{14}$ Segundo Barboza, a essência da mensagem de Aforismos afirma que, "desde que se evite a atração das desgraças por atos tolos, e para isso serve uma vida sábia, é de fato possível trilhar o caminho de uma boa qualidade de vida, em meio a esse quase inferno que é o mundo". ${ }^{15}$ Embora seja absolutamente necessário "ser o que se é", conhecendo o que quer e o que pode, o homem aprende a agir de modo mais saudável e seguro.

Não estaríamos diante de um estranho tipo de "liberdade" que talvez possa ser concebida como uma "liberdade de ser o que se ê"? E não seria esta a "liberdade que nos resta"? Ao que tudo indica, essa "estranha liberdade" pode ser explorada no sentido de uma melhor qualidade de vida, como um meio de um "aprender a lidar com o que se é", que corresponde ao caráter adquirido, bem como à orientação pelas "máximas" anunciadas didaticamente por Schopenhauer em Aforismos para a Sabedoria de Vida. Segundo Brum, essa obra apresenta "uma atitude prática que pode servir de antídoto ao niilismo de sua visão ascética, [...] uma maneira positiva de enfrentar o "mal de viver"" (BRUM, 1998, p. 50). Trata-se aqui da "liberdade" de modificar a conduta no curso de nossa existência, aprendendo, pela experiência, a "arte de conduzir a vida do modo mais agradável e feliz possível" (ASV, p. 1). Deste modo, pode-se afirmar que a impossibilidade de liberdade da vontade, em Schopenhauer, não nos impede de ter uma lucidez positiva de enfrentamento da vida, aprendendo o trato com o que nos é inevitável, ou mesmo a possibilidade de fazer arte com aquilo que somos.

14 Ver, por exemplo, a máxima 30: "Nenhum caráter é de tal modo talhado que possa ser abandonado a si mesmo, vagueando incerto daqui para acolá, mas cada um precisa ser guiado por conceitos e máximas" (ASV, p. 215).

15 BARBOZA, J. Em favor de uma boa qualidade de vida. Prefácio. In: ASV, p. XV. 


\section{Referências}

ANDERS, G. Kafka: pré e contra. Os autos do processo. São Paulo: Perspectiva, 1969.

BARBOZA, J. Em favor de uma boa qualidade de vida. Prefácio. In: ASV, p. XV.

BENJAMIN, W. Franz Kafka. A propósito do décimo aniversário de sua morte. In: Magia e técnica, arte e política. Ensaios sobre literatura e história da cultura. São Paulo: Brasiliense, 1994. p. 141-142. (Obras escolhidas; v. 1).

BRUM, J. T. O pessimismo e suas vontades: Schopenhauer e Nietzsche. Rio Janeiro: Rocco, 1998.

CACCIOLA, M. L. M. O. Schopenhauer e a questão do dogmatismo. São Paulo: EDUSP, 1994.

HELLER, E. Kafka. Tradução de James Amado. São Paulo: Cultrix, 1976.

KAFKA, F. O processo. Tradução de Modesto Carone. São Paulo: Brasiliense, 1992.

Um artista da fome e a construção. Tradução de Modesto Carone. São Paulo: Companhia das Letras, 1998.

MAGGE, B. The philosophy of Schopenhauer. New York: Oxford, 1983.

RADAKRISHNAN, S. Indian philosophy. Nova Delhi: Oxford, 1923.

RAMOS, F. C. 'A hora da morte'- Borges leitor de Schopenhauer. In: SALLES (Org.). Schopenhauer e o idealismo alemão. Salvador: Quarteto, 2004. p. 75.

SCHOPENHAUER, A. Die welt als wille und vorstellung. Sämmtliche Werke. Textkritisch bearbeitet und herausgegeben von Wolfgang Frhr. von Löhneysen. Frankfurt am Main: Suhrkamp, 1986.

Le monde comme volonté et comme représentation. 13. ed. Tradução de A. Burdeau (nouv. éd. rév. et corr. par R. Roos). Paris: Universitaires de France, 1992.

O mundo como vontade e como representação. Tradução de Jair Barboza. São Paulo: UNESP, 2005. 
Parerga and paralipomena. Tradução de E. F. J. Payne. New York: Oxford, 2000. v. 1, 2.

Parerga e paralipomena. Tradução de. M. L. M. O. Cacciola. São Paulo: Nova Cultural, 1991. Cap. V, VIII, XII, XIV.

Essai sur le libre arbitre. Tradução de Salomon Reinach. Paris: Librarie Félix-Alcan, 1913.

. Aforismos para a sabedoria de vida. Tradução de Jair Barboza. São Paulo: Martins Fontes, 2002.

Sobre o fundamento da moral. Tradução de Maria Lúcia M. O. Cacciola. São Paulo: Martins Fontes, 1995.

Metafísica do belo. Tradução de Jair Barboza. São Paulo: Unesp, 2003.

Metafísica do amor, metafísica da morte. Tradução de Jair Barboza. São Paulo: Martins Fontes, 2000.

VECCHIOTTI, I. Schopenhauer. Lisboa: Edições 70, 1986.

Recebido em: 11/07/2007

Received in: 07/11/2007

Aprovado em: 31/07/2007

Approved in: 07/31/2007 